\title{
AdVERbial QUaNTIFiCATION AND Focus in HaUSa
}

\author{
Malte Zimmermann \\ Humboldt Universität Berlin \\ malte.zimmermann@rz.hu-berlin.de
}

\begin{abstract}
The paper investigates the interaction of focus and adverbial quantification in Hausa, a Chadic tone language spoken in West Africa. The discussion focuses on similarities and differences between intonation and tone languages concerning the way in which adverbial quantifiers (AQs) and focus particles (FPs) associate with focus constituents. It is shown that the association of AQs with focused elements does not differ fundamentally in intonation and tone languages such as Hausa, despite the fact that focus marking in Hausa works quite differently. This may hint at the existence of a universal mechanism behind the interpretation of adverbial quantifiers across languages. From a theoretical perspective, the Hausa data can be taken as evidence in favour of pragmatic approaches to the focus-sensitivity of AQs, such as e.g. Beaver \& Clark (2003).
\end{abstract}

\section{Introduction}

The paper investigates the semantic effects of grammatical focus marking and focusbackground structure on adverbial quantification in Hausa, a Western Chadic tone language, which is spoken mainly in Northern Nigeria and the Republic of Niger. ${ }^{*}$ The discussion focuses on similarities and differences between intonation and tone languages concerning the way in which adverbial quantifiers, henceforth AQs, and focus particles, henceforth FPs, associate with focus constituents. The main purpose of the paper is to introduce new empirical data from a semantically under-researched language into the theoretical debate. It will emerge that typologically diverging languages do not differ much in how adverbial quantification and focus-background structure interact. Concerning their relevance to the theoretical debate, the Hausa data may be taken as evidence in favour of more pragmatically oriented approaches to the analysis of AQs, and to the interpretation of focus in general.

The paper is organized as follows. Section 2 provides a quick overview over the interaction of adverbial quantification and focus-background structure in intonation languages, such as English and German. Section 3 introduces the focus marking system of Hausa, which differs a lot from the accent-based focus-marking systems of intonation languages. Section 4 contains a few methodological remarks on semantic fieldwork in general. The core part of the paper is section 5, which presents the main empirical findings concerning the interaction of adverbial quantifiers and focus-background structure in Hausa. Section 6 provides a sketch for a unified analysis of AQs in Hausa and intonation languages, which gives rise to a prediction for the behaviour of AQs in intonation languages. Section 7 concludes.

\section{Adverbial Quantification and Focus in Intonation Languages}

Most, if not all semantic accounts of adverbial quantification are based on intonation languages, which mark focus prosodically by means of a nuclear pitch accent. In these

\footnotetext{
* This article was written within the project B2 "Focusing in Chadic Languages" funded by the German Science Association (DFG) as part of the SFB 632 „Information Structure“. I would like to express my gratitude to the DFG, as well as to my Hausa consultants Malama Aisha Mahmud Abubakar, Malama Sa'adatu Garba, Malam Umar Ibrahim, Malam Rabi'u Shehu, Malam Balarabe Zulyada'ini, as well as Malam Mu'awiya for their patience and willingness to place themselves into ever more bizarre fictitious contexts. I am solely responsible for any errors and omissions.
} 
languages, AQs exhibit focus sensitivity in that grammatical focus marking has a truthconditional effect on their interpretation, see e.g. Lewis 1975, Rooth 1985, 1992, Partee 1991, von Fintel 1994, Herburger 2000, among many others. To recapitulate, consider the sentences in (1a-c), where a change in accent position induces a change in meaning:
a. MUSA always eats rice.
SUBJ-focus
b. Musa always EATS rice.
$V$-focus
c. Musa always eats RICE.
OBJ-, VP-, sentence-focus

Following work by Partee (1991), semantic accounts of the focus-sensitivity of AQs try to capture their interpretation in terms of tripartite structures: the semantic representation of clauses containing an AQ is split up into three parts depending on their focus-background structure: the AQ is the quantificational operator, the background is mapped on the restriction of the quantifier, and the focus constituent is mapped on the nuclear scope of the quantifier. This is illustrated for (1a-c) in (2). ${ }^{1}$

(2)
Operator
Restriction
Nuclear scope
a. always $_{\mathrm{e}} \quad(\exists \mathrm{x} \mathrm{x}$ eats rice at $\mathrm{e}) \quad$ (Musa eats rice at $\left.\mathrm{e}\right)$ = Always, if somebody eats rice, it is MUSA.
b. always e ( $\exists \mathrm{R}$ Musa R-s rice at e) (Musa eats rice at e) $=$ Always, if Musa does something with rice, he EATs rice.
c. always $_{\mathrm{e}} \quad(\exists \mathrm{y}$ Musa eats y at e) (Musa eats rice at e) = Always, if Musa eats something, he eats RICE. (= OBJ-focus)

A first empirical generalisation that emerges from (1) and (2) is given in (3):

\section{Focus-Sensitivity of AQs:}

The grammatically marked focus constituent is never mapped to the restriction, but to the nuclear scope of the AQ (Partee 1991).

According to (3), there is a tight relation between grammatical focus marking and the interpretation of AQs. In addition, semantic accounts assume an equally tight connection between the background of a clause and the semantic restriction of the AQ: according to this assumption, the background of a clause, with the focus constituent replaced by a variable, would be automatically mapped to the restriction. A variant of this proposal is found in Rooth (1999), where it is assumed that AQs do not associate with focus per se, but rather with the presuppositions induced by the focus-background structure of the clause.

However, recent studies of the focus-sensitivity of AQs have cast some doubt on the validity of the second claim. Cohen (1999) and Beaver \& Clark (2003), henceforth B\&C (2003), discuss a number of examples in which the background, i.e. material that is not grammatically marked for focus, is not automatically mapped to the restriction of the AQ. Consider (4) from B\&C (2003:336, ex. (31)):

(4) Mary always took someone $e_{F}$ to the cinema.

The meaning of the background in (4) can be paraphrased as 'Mary took $\mathrm{x}$ (=someone) to the cinema'. Given the above assumption that the background is automatically mapped on the restriction of the $\mathrm{AQ}$, the meaning of the entire clause in (4) should therefore be the

\footnotetext{
1 For the sake of simplicity, I assume without further argument that adverbial quantifiers quantify asymmetrically over events or situations only. See e.g. Heim (1990), de Swart (1991), and von Fintel (1994) for relevant discussion.
} 
tautological 'Always, if Mary took someone to the cinema, she took someone to the cinema.', contrary to fact. Rather, the meaning of (4) can be paraphrased as in (4')

(4') Always, if Mary went to the cinema, she took someone with her.

The restriction of always in (4) is implied by, but not identical to the background of (4). Based on the interpretation of sentences such as (4), we therefore arrive at a second generalisation concerning the interaction of AQs with focus-background structure:

\section{No direct association with backgrounded material:}

Backgrounded material, i.e. material that is not grammatically marked for focus, is not automatically mapped to the restriction of the AQ (see also B\&C 2003: 340)

Rather, it seems that the contribution of the background to the identification of an AQ's restriction is more indirect and mediated by the pragmatics.

Finally, even though AQs are focus-sensitive, they differ from focus particles (FPs) such as only in that they stand in a loser semantic (and syntactic) relation to the focus constituent (B\&C 2003: 348ff.). This is illustrated by the degraded status of (6), a variant of (4) with always replaced by the - at first sight synonymous - FP only (B\&C's (32)):

?Mary only took someone $_{F}$ to the cinema.

To the extent that it is acceptable, (6) can only mean something like 'the single person that Mary took to the cinema was someone', which is not very informative to say the least. The difference between AQs and FPs also shows up in the minimal pair in (7ab) (B\&C's exs. (3) and (4)): The variant with only is ungrammatical, but the variant with always is fine:

a. *Sandy only feeds Nutrapup to Fido $o_{F}$, and she only feeds Nutrapup to Butch $_{F}$ too.

b. Sandy always feeds Nutrapup to Fido ${ }_{F}$, and she always feeds Nutrapup to Butch $_{F}$ too.

B\&C (2003) account for these differences by assuming that FPs such as only are focusfunctional: they make direct reference to the focus-background structure of a clause in their truth-conditions, and often in form of syntactic licensing conditions as well. The truthconditions for sentences containing the FP only are stated in (8a). Compare these with the truth-conditions for sentences containing the AQ always in (8b) (B\&C 2003: 349):

a. $[[\mathrm{NP}$ only $\mathrm{VP}]]=\forall \mathrm{e}[\mathrm{p}(\mathrm{e}) \rightarrow \mathrm{q}(\mathrm{e})]$

(with $\mathrm{q}=[[N P V P]]$, and $p=[[N P V P]]$ minus the content of focused material within the $V P$ )

b. $[[\mathrm{NP}$ always $\mathrm{VP}]]=\forall \mathrm{e}\left[\sigma(\mathrm{e}) \rightarrow \rho\left(\mathrm{e}, \mathrm{e}^{\prime}\right) \wedge \mathrm{q}\left(\mathrm{e}^{\prime}\right)\right]$

(with $q=\left[\begin{array}{ll}{[N P} & V P\end{array}\right], \sigma$ a contextually constrained variable over sets of situation, and $\rho$ a contextually constrained variable over relations between events)

According to (8a), (7a) states that the only event of Sandy feeding somebody with Nutrapup is an event of Mary feeding Nutrapup to Fido, and the only event of Sandy feeding somebody with Nutrapup is an event of Mary feeding Nutrapup to Butch. As both conjuncts are uttered in the same context, this is clearly contradictory. In contrast, the interpretation of clauses with AQs such as always is largely governed by pragmatic factors. The connection between the restriction of always, $\sigma$ in $(7 \mathrm{~b})$, and the focus-background structure of the clause is established indirectly, in that $\sigma$ must not contradict the presuppositions of the clause, including those stemming from its focus-background structure. For this reason, (7b) can receive an interpretation that is not contradictory, given appropriate values for $\sigma$ and $\rho$. For example, if $\sigma$ is the sets of events in which Sandy feeds some number of dogs, and if $\rho$ is the temporal-andphysical-part-of relation, then (7b) would state that in every event in which Sandy feeds some dogs, she feeds Nutrapup to Fido, and in every event in which Sandy feeds some dogs, she 
feeds Nutrapup to Butch (but she does not, say, feed Nutrapup to Cuddles because he is too old and has no teeth left) (see B\&C 2003: 352). In this case, the restriction $\sigma$ would not contradict the background presupposition of (7b), according to which Mary feeds Nutrapup to someone. The difference between AQs and FPs is stated again in (9):

(9) Adverbial quantifiers stand in a loser semantic and syntactic relation to the focus constituent than focus particles.

Notice finally that the generalisation in (3) still holds. Since the meaning of the entire clause, q, is mapped to the nuclear scope of the AQ always (see also Partee 1999), it follows that the meaning of the focus constituent will be mapped to its nuclear scope, too. However, the effect of grammatical focus marking on the interpretation of AQ-sentences is only indirect: the focus-sensitivity of AQs arises because their interpretation depends on a contextually-salient set of events, $\sigma$, and because focus-marked material is usually not contextually salient and therefore not part of $\sigma$, see once again B\&C (2003: 348).

\section{Focus Marking in Hausa}

This section discusses the basic patterns of grammatical focus marking in Hausa. Section 3.1 gives some general information on Hausa, which will ensure a better understanding of the empirical data to be introduced later. Section 3.2 shows how focus is grammatically marked in Hausa. Section 3.3. demonstrates that such focus marking is not obligatory with nonsubjects, resulting in massive focus ambiguity.

\subsection{General Information on Hausa}

Hausa belongs to the Western branch of the Chadic language family, which belongs to the Afro-Asiatic languages. Its grammatical system is well documented, see e.g. the grammars by Newman (2000) and Jaggar (2001). Hausa is a tone language with three lexical tones: a high tone, a low tone ( $)$, and a falling tone $\left({ }^{\wedge}\right)$. The basic word order is SVO and pronominal subjects can be dropped. Hausa has no overt case marking, which means that arguments are identified by their position relative to the verb and by subject agreement. Oblique arguments are marked by prepositions. The verb is not inflected for tense or agreement. Instead, temporal and aspectual information as well as subject agreement are encoded by means of a TAM-marker preceding the verb: The TAM-marker taa in (10), for instance, indicates that the subject is 3 sg.f and that the sentence is in the perfective aspect.

$$
\begin{array}{lll}
\text { Kànde taa } & \text { dafà } & \text { kiifii. } \\
\text { Kande 3sg.f.perf } & \text { cook } & \text { fish } \\
\text { 'Kande cooked fish.' } & &
\end{array}
$$

In the progressive aspect, the verb appears in its nominalized form. With many verb classes, this verbal noun and the following complement are linked by the nominal linker $-n /-r$ 'of', which is typically found in associative $N-o f-N$-constructions, cf. (11):

(11) Ya-nàa $\quad \begin{aligned} & \text { gyaara-n } \\ & \text { repairing-of }\end{aligned}$
$\begin{aligned} & \text { 3sg.mootaa. } \\ & \text { car }\end{aligned}$
'He is repairing the car.'

\subsection{Grammatical Focus Marking}

Focus in Hausa is not marked by pitch accent, but syntactically: the focus constituent is moved to a focus position in the left periphery. Like other instances of A'-movement, such as $w h$-fronting and relativization, focus movement is indicated by a morphological change in the aspectual marker, which appears in the so-called relative form (Tuller 1986). In addition, the fronted focus constituent is optionally followed by the particle nee/cee, see e.g. Green (1997), 
and Newman (2000). ${ }^{2}$ (12a) exhibits the neutral SVO order. In (12b), a focused object NP has been fronted. (13) illustrates focus fronting with a PP-adjunct.

a.

$\begin{array}{lll}\text { Kànde taa } & \text { dafà } & \text { kiifii. } \\ \text { Kande 3sg.f.perf } & \text { cook } & \text { fish } \\ \text { 'Kande cooked fish.' } & & \end{array}$

b. Kiifii $1_{1}$ (nèe) Kànde ta dafàa $\mathrm{t}_{1}$. fish PRT Kande 3sg.f.perf.rel cook 'Kande cooked FISH.'

Dà wuKaa nèe $_{1}$ ya sòokee shì $\mathrm{t}_{1}$. (Newman 2000:192) with knife PRT 3sg.perf.rel stab him 'He stabbed him with a KNIFE.'

In contrast, focused subjects are focus-marked by (vacuous) movement: in the progressive and perfective aspect, the focus status of the subject is marked on the TAM-marker, which appears in the relative form. Thus, (12a) could not be used to answer the subject question 'Who cooked fish?'. Instead, one would have to use (14) with a short-voweled relative aspect marker (and optional particle).

$\begin{array}{llll}\text { Kànde }_{\mathrm{F}, 1}(\mathrm{cèe}) \mathrm{t}_{1} & \mathrm{t} a & \text { dafà } & \text { kiifiii. } \\ \text { Kande PRT } & \text { 3sg.f.perf.rel cook } & \text { fish } \\ \text { 'KANDE cooked fish.' } & & \end{array}$

Section 5.1 will demonstrate how the fronting of different focus constituents effects the interpretation of adverbially quantified sentences.

\subsection{No Obligatory Focus Marking with Non-Subjects}

Closer scrutiny of the focus facts in Hausa shows that focused non-subjects need not be fronted, but can also remain in situ (Green and Jaggar 2003). As a matter of fact, the in situ variant is the preferred option with new-information focus (Hartmann and Zimmermann, to appear-a). Instances of in situ focus are grammatically unmarked, that is, they are marked neither syntactically nor prosodically, e.g. by pitch movement, duration or intensity (Hartmann and Zimmermann, to appear-a). (15A) illustrates such an unmarked focus constituent (dawaakii) in an answer to a wh-question:

$$
\begin{array}{lllll}
\text { Q: } & \text { Mèe su-kà } \quad \text { kaamàa? } & \text { A: } & \text { Sun kaamà dawaakii }{ }_{\mathrm{F}} & \text { (nè). } \\
\text { what 3pl-perf.rel catch } & & \text { 3pl.perf catch horses } & \text { PRT } \\
\text { 'What did they catch?' } & & \text { 'They caught HORSES.' }
\end{array}
$$

In this respect, Hausa differs drastically from intonation languages, which invariably have a (focus-marking) pitch accent somewhere in the clause, and which therefore exhibit obligatory focus marking.

The optional lack of focus marking leads to a considerable degree of focus ambiguity, which must be pragmatically resolved. The SVO order in (15A) could thus be used to answer the questions 'What did Kande cook?' (OBJ-focus), or 'What did Kande do?' (VP-focus), as well as 'What happened?' (sentence focus). This raises the question of how the absence of

\footnotetext{
2 The particle nee/cee has received various analyses in the literature. Traditionally, it is called a stabilizer (Newman 2000). Alternatively, the particle has been analysed as a copula element in a cleft-like construction (McConvell 1973), or as a focus marker (Green 1997). Most recently, Hartmann and Zimmermann (to appear-b) provide semantic arguments that nee/cee should be analysed as a focus-sensitive marker of exhaustivity. As nothing hinges on the correct choice for the purposes of this article, I will simply gloss nee/cee as a particle (PRT).
} 
grammatical focus marking with non-subjects affects the meaning of sentences with AQs. We will turn to this question in section 5.2.

Notice again, that unlike all other constituent, focused subjects must be marked. Presumably, this restriction, which is found in many African languages (Hartmann \& Zimmermann 2004), has a functional origin. In their unmarked preverbal position, subjects frequently receives a default interpretation as topic of the clause (Givon 1976, Chafe 1976). Consequently, a subject will have to be marked whenever it does not function as the topic of the clause, for instance when it is focused.

Summing up, focus in Hausa is marked syntactically by fronting, and morphologically by a change in form of the perfective and progressive TAM-markers. Hausa differs from European intonation languages in that focus may, but need not be grammatically marked. This means that many instances of focus must be resolved pragmatically, based on the context: This is the case with non-subject foci that are realised in situ, as well as with instances of subject focus in the future and habitual aspect, both aspects without relative TAM-marking.

\section{Methodological Remarks on Semantic Fieldwork}

Before we turn to the actual discussion of the focus-sensitivity of AQs in Hausa, a few general remarks on the methodology of semantic fieldwork are in order. After all, asking language consultants about meanings is difficult, especially when it comes to the subtle meaning differences arising from the interaction of AQs with the focus-background structure of a clause. Because of this problem, the Hausa data were collected following Matthewson's (2004) methodological guidelines for semantic fieldwork.

According to Matthewson (2004), the only licit elicitation methods for semantic fieldwork are the ones listed under (16):

(16) i. Translations of entire clauses

ii. Truth-condition judgments relative to a context

iii. Felicity judgments relative to a context

In each case, the elicitation of judgments is achieved by asking whether a particular clause A is appropriate in a previously set up discourse context or situation.

A particularly daunting problem in the semantic analysis of sentences in a foreign language arises in connection with potentially ambiguous sentences. Straight translation tasks from the object language into the metalanguage generally fail, as the language consultant usually translates the sentence on its most prominent reading, afterwards rejecting translations of less prominent readings. In order to establish the meanings of potentially ambiguous clauses, one should therefore stick to the following strategies, the first three of which are taken from Matthewson (2004):

(A) Never ask the consultant directly for an ambiguity judgment as this would be asking for an analysis. There is the danger that consultants may overlook or even discard less prominent readings. Instead,

(B) if you have a suspicion what the less preferred reading may be, ask for this reading first, by setting up an appropriate context and then asking for a truth-condition or felicity judgment.

(C) Choose examples that pragmatically force the less preferred reading.

In order to illustrate how one reading can be pragmatically forced over another, consider adverbially quantified transitive clauses in English with a pitch accent on the object NP. The pitch accent could indicate focus on the VP or on the object. Assume now that we want to test for the association of the AQ with object focus. In order to do so, one should look for an 
example such as (17), which would make the VP-focus reading highly unlikely, or even false, due to our world knowledge. (17) is modelled on Hausa data actually used in the elicitation.

(17) Hausa people mostly [vP eat [NP TUWO]].

On the VP-reading, without any further context, (17) states that on most occasions on which Hausa people do anything, they eat tuwo, a kind of mush made form cassava, yams, rice or grain, which is eaten with almost any meal. As Hausa people usually do not spend the larger part of the day eating, (17) should be judged unlikely or even false on this reading. In contrast, on the OBJ-reading, (17) states that on most occasions on which Hausa people eat anything, they eat tuwo. Given the above remark on the eating habits of Hausa people, this is correct. The difference in truth-conditions or felicity between the two readings, therefore makes (17) a good test case for the existence of association with object focus.

(D) Control for the focus constituent in a clause by adding material in form of negative contrastive clauses, which serve to disambiguate the focus-background structure.

The Hausa example in (18) illustrates strategy (D). The first clause is at least four-ways ambiguous between an OBJ-, VP-, a sentence-focus, or even a SUBJ-focus reading, as there is no relative TAM-marker in the habitual aspect. Disambiguation is achieved by adding a negative contrastive, which is identical to the first clause except for the contrastive focus constituent riigunàa 'dresses':

$$
\begin{aligned}
& \text { Yawanci madìnki ya-kàn yi huulunàa, baa-yàa yî-n } \\
& \text { mostly tailor 3sg.m-hab make caps riigunàa } \\
& \text { 'In most instances, a tailor makes HATS, not SHIRTS.' }
\end{aligned}
$$

The resulting structure in (18) only has the OBJ-focus reading because it is the object that is contrastively focused under negation. This discussion of the methods used in eliciting semantic data in Hausa sets the stage for the upcoming discussion of the interaction of Hausa AQs with focus.

\section{Adverbial Quantification and Focus Marking in Hausa}

This section presents the empirical findings concerning the semantic interaction of Hausa AQs such as kullum 'always', yawanci/galibii 'mostly/usually' and the habitual aspect marker -kan with the focus-background structure in that language. We will consider cases with grammatical focus marking and cases without grammatical focus marking in turn. Section 5.1 shows hat Hausa AQs are sensitive to grammatical focus marking. Section 5.2 discusses the interpretation of adverbially quantified sentences in the absence of grammatical focus marking. Section 5.3 deals with differences between AQs and FPs in Hausa.

A major result of the discussion is that the interaction of AQs with the focus-background structure in Hausa is very similar to that found in intonation languages, despite the observed differences in the way that focus is grammatically marked. Furthermore, the discussion shows that the correct interpretation of adverbially quantified sentences in Hausa relies heavily on contextual information, especially when focus is not grammatically marked. The fact that the interpretation of AQs in Hausa is governed by pragmatic factors can be taken as another argument in favour of pragmatic approaches to the interpretation of AQs in general.

\subsection{Hausa AQs are Sensitive to Grammatical Focus Marking}

The investigation of the interaction of Hausa AQs with instances of grammatically marked focus shows that Hausa AQs are sensitive to the focus-background structure induced by grammatical focus marking, just like their counterparts in intonation languages. The focusmarked constituent must be mapped onto the nuclear scope and not onto the restriction of the AQ. The interpretation of the sentences in (19) and (20) differs accordingly, depending on which constituent is focus-marked by means of movement to a left-peripheral position. 


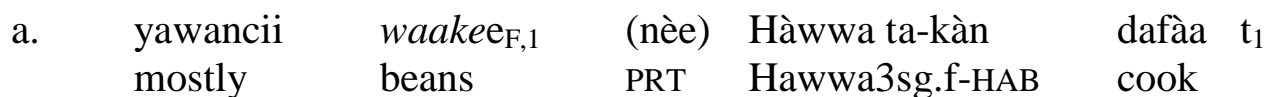
'Most times, if Hawwa cooks something, it is beans.'
b. yawancii $H a ̀ w w a_{F, 1}$ cèe $\mathrm{t}_{1}$ ta-kàn dafà waakee mostly Hawwa PRT 3sg.f-HAB cook beans
'Most times, if somebody cooks beans, it is Hawwa.'
$O B J$

In (19a), the object has been fronted, and the AQ ranges over sitations in which Hawwa cooks something (in the absence of further contextual information). In (19b), the subject has been fronted, and the AQ ranges over sitations in which somebody cooks beans. Notice that the focus status of the subject in $(19 \mathrm{~b})$ is indicated by the presence of the optional particle cee. The examples in (20a-c) serve to illustrate the same point for ditransitive clauses, with focus on the direct object, indirect object, and subject respectively.
a. kullum $k u d^{\prime} i i_{\mathrm{F}, 1}$ (nee) na-kèe bâ Audù $\mathrm{t}_{1}$ always money PRT 1sg-prog.rel give Audu 'It is money that I always give to Audu.'
b. kullum Audì̀,1 (nee) na-kèe bâ $\mathrm{t}_{1} \quad$ kud'ii. always Audu PRT 1sg-prog.rel give money 'It is to Audu that I always give money.'
c. kullum $n i i_{\mathrm{F}, 1}$ (nèe) $\mathrm{t}_{1}$ na-kèe bâ Audù kud'ii. always 1sg PRT 1sg-prog.rel give Audu money 'Always I myself give money to Audu.'
d. kullum nèe na-kèe bâ Audù kud'ii. always PRT 1sg-prog.rel give Audu money ,It is every day that I give Audu money.'
$O B J$

As (20d) shows, it is also possible to mark focus on the AQ itself.

The minimal pair in $(21 \mathrm{ab})$ does not differ in terms of word order. On the surface, both sentences show the unmarked word order SVO. Nonetheless, the relative TAM-marker takèe in (21b) marks the subject as being in focus. Correspondingly, the AQ kullum 'always' ranges over situations in which someone is cooking beans, stating that it is always Hawwa who is cooking beans. That the subject Hawwa is indeed in focus, can be seen from the fact that the sentence is considered inappropriate if two women are cooking beans, in particular if the particle cee is present. ${ }^{3}$

$\begin{array}{llll}\text { (21) a. } & \text { Kullum Hàwwa ta-nàa dafà waakee. } & \text { OBJ } \\ \text { always Hawwa 3sg.f-prog cook beans } & \\ & \text { 'Always, Hawwa is cooking BEANS.' } \\ & \text { (consultant's comment: She does not have to cook anything else) }\end{array}$
b. Kullum Hàwwa $\mathrm{F}, 1_{1}$ (cèe) $\mathrm{t}_{1}$ ta-kèe dafà waakee. always Hawwa PRT 3sg.f-prog.rel cook beans
'It is HAWWA that is always cooking the beans.'

\footnotetext{
${ }^{3}$ At first sight, the exhaustivity effect in (21b) appear to be in contradiction to the non-exhaustive behaviour of always in English, which was pointed out in connection with the Fido-Butch-example in (7ab). I would like to contend, though, that the observed exhaustivity effect does not follow from the presence of the AQ kullum, but that it is either a semantic effect of the overt syntactic focus construction (à la Kiss 1998), or - more likely - that it follows from the presence of nee/cee, if nee/cee is indeed an exhaustivity marker as argued by Hartmann and Zimmermann (to appear-b), cf. fn.2. In any event, the fact that it is the subject Hawwa that is exhaustively quantified over shows clearly that Hawwa must be the focus of the utterance, as the exhaustivity operator typically ranges over the focus domain.
} 
In (21a), on the other hand, there is no focus marking at all. As the consultant's comment shows, (21a) can receive a reading on which the AQ is interpreted relative to the focused object NP, and on which it states that whenever Hawwa cooks something, she cooks beans. We will turn to the interpretation of sentences without focus marking shortly.

Concluding this section, let us briefly take note that - perhaps not surprisingly - the interpretation of adverbially quantified sentences in other Chadic languages also depends on the focus structure of the clause. The examples in (22a-c) are taken from Gùrùntùm, another Western Chadic language, whose focus marking system differs from the Hausa one in two ways: First, focus in Gùrùntùm is marked morphologically by means of a focus marker $a$ on the focus constituent. This a-marker precedes the focus constituent in case of NP- and PPfocus, and follows the focus constituent in case of sentence focus. Second, constituent focus is obligatorily marked. These differences notwithstanding, the data in (22a-c) illustrate that AQs in Gùrùntùm show the same kind of focus sensitivity as their counterparts in Hausa, or - for that matter - in intonation languages.

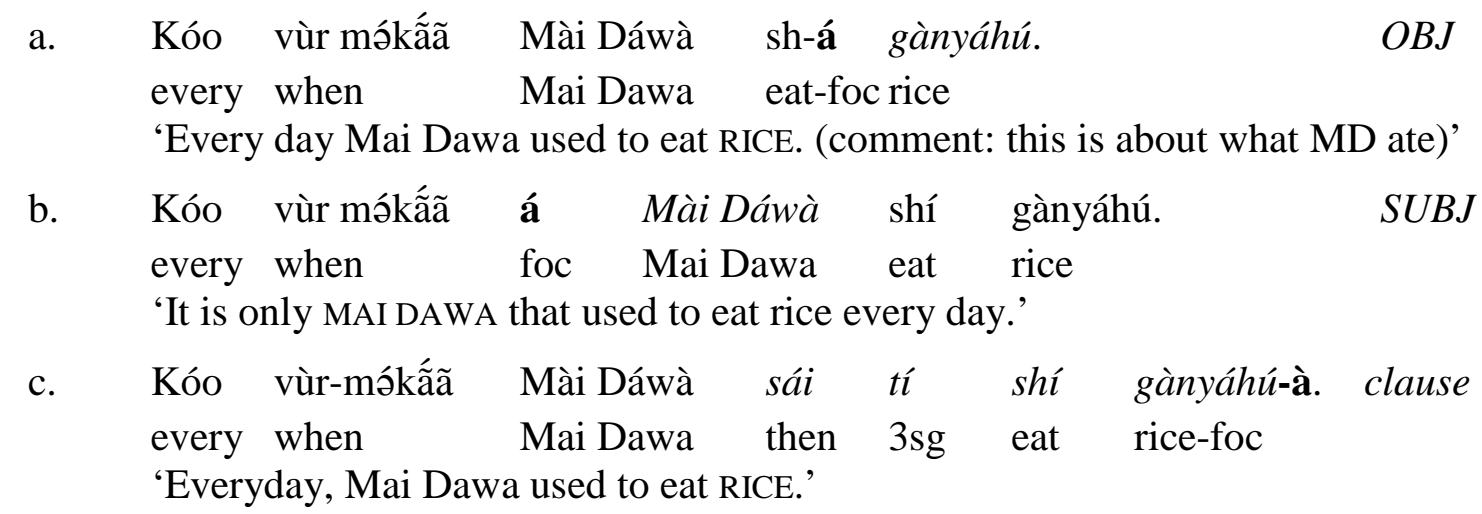

In all three sentences, the syntactic position of the focus marker $a$ in the clause has an effect on the interpretation of the AQ: The focus-marked constituent ends up in the nuclear scope of the adverbial quantifier. ${ }^{4}$

\subsection{The Interpretation of AQs in the Absence of Focus Marking}

Hausa AQs can also associate with material that is not grammatically focus-marked. This happens whenever focus is grammatically unmarked, such that the grammar imposes no constraints on the focus-background structure. In such cases, the association of the AQ with the unmarked focus constituent seems to be determined solely by pragmatic factors.

It is important that here as elsewhere, the phrasing 'the AQ associates with $\mathrm{X}$ ' is intended as a shorthand for 'the AQ is interpreted relative to a sentence with focus on $\mathrm{X}$ '. In this respect, Hausa AQs differ from focus particles, which will be shown to truly associate with a focus constituent in the sense that they depend on a clearly identifiable focus constituent for a proper interpretation, see section 5.3.

The fact that AQs can occur in the absence of focus marking raises the question of whether the AQ can associate with more than one constituent in the clause in such cases. The following data suggest that this question can be answered in the affirmative: adverbially quantified sentences without grammatical focus marking are ambiguous between various

\footnotetext{
${ }^{4}$ Example (22c), where entire clause tí shí gànyáhúà 'He ate rice' is in focus, is particularly interesting. Apparently, association of the AQ with the full clause is possible only once the clause has been emptied of all topic-like material, such as the preverbal subject MaiDawa, which is replaced by the pronoun tí. Evacuation of the topic MaiDawa leads to a syntactic tripartition into AQ, topic, and clause, which may very well be an overt reflex of the semantic representation of the sentence. Given the limited amount of data available, though, further clarification of this issue must await further research.
} 
readings. The focus ambiguities that arise from the absence of focus marking are listed in (23) (abstracting away from foci on non-maximal constituents for ease of exposition):

\section{Focus ambiguities arising from the absence of focus marking:}

i. perfective/progressive: $\quad \mathrm{VP}, \mathrm{OBJ}$, sentence

ii. in all other aspects:

VP, OBJ, SUBJ, sentence

Recall that the focus status of subjects must be indicated by a relative TAM-marker in the perfective and in the progressive aspect. It follows that sentences without focus marking are at least three-ways ambiguous in these two aspects, cf. (23i). In the habitual and future aspect, where there are no relative TAM-markers, sentences without focus marking are even fourways ambiguous, cf. (23ii) and (18) above.

The ambiguity of adverbially quantified sentences without focus marking creates a methodological problem already raised in section 4: in spontaneous translation tasks, the $\mathrm{VP}_{\mathrm{FOC}}$-reading, and where applicable the $\mathrm{SUBJ}_{\mathrm{FOC}}$-reading, is often the dominant reading, thus suppressing the $\mathrm{OBJ}_{\mathrm{FOC}}$-reading. In order to check for the availability of the less prominent $\mathrm{OBJ}_{\mathrm{FOC}}$-reading, we therefore have to fall back on the methodological tools discussed in section 4 in connection with (17) and (18), i.e. strategies (C) and (D).

The progressive sentences in (24) and (25) below illustrate strategy (C). The possibility of subject focus is excluded, as the TAM-marker does not appear in its relative form. The sentences are all of the form The $Y$ usually drink $X$, such that the $\mathrm{VP}_{\mathrm{FOC}}$-reading would state that in most situations in which the $\mathrm{Y}$ do anything they drink $\mathrm{X}$. The lexical material was chosen in such a way that the $\mathrm{VP}_{\mathrm{FOC}}$-reading is most likely to be false, or at least highly implausible in the absence of further contextual information. In order to check for the availability of the $\mathrm{OBJ}_{\mathrm{FOC}}$-reading, we varied the object and subject NPs in such a way that the resulting sentences should be true on this reading with some NP-combinations (the pairings Hausa people - kunu, and Europeans - coca cola), but false with others (the pairings Hausa people - coca cola, and Europeans - kunu). Indeed, the consultants' reactions, which are indicated after the relevant examples, matched these expectations. (24a), with the pairing Hausa people - kunu, was judged to be true. (24b), on the other hand, with the pairing Hausa people - coca cola, was strongly rejected.
a. Yawanci
mostly
hausawa
su-nàa shân
Hausa.people 3pl-prog drinking
kùunú
$\rightarrow$ true
'Most times, Hausa people drink kunu.'
b. Yawanci
mostly
hausawa
su-nàa shân
Hausa people 3pl-prog drinking
'Most times, Hausa people drink coca cola.'
coca-cola $\rightarrow$ not true!
coke.

Conversely, (25a), with the pairing Europeans - kunu, caused amusement on the side of the consultants, whereas (25b), with the pairing Europeans - coca cola, was deemed appropriate:
a. Yawanci
mostly
turawa
Europeans
su-nàa shân
3pl-prog drinking
kùunú
kunu
'Most times, Europeans drink kunu.'
b. Yawanci mostly
turawa
su-nàa shân
Europeans
3pl-prog drinking
coca-cola
coke.
'Most times, Europeans drink coca cola.'

The observed systematic variation in the judgments indeed seems to suggest that the AQ, here yawanci 'usually, most times', associates with the object NP in (24) and (25), in particular as this reading is the easiest to construe in the absence of further contextual information. It should be noted, though, that the observed judgments do not provide waterproof evidence 
against a VP-focus, or even sentence focus interpretation of (24) and (25). After all, situations of Hausa people drinking kunu are perceived as more normal than Hausa people drinking coke (and conversely for the Europeans). It follows that interpretations such as 'Whenever Hausa people do anything, they drink kunu' (VP-focus) or 'Whenever something happens, Hausa people drink kunu' (sentence focus) are more likely to be accepted as true as their counterparts with kunu replaced by the Western (or rather Northern) drink coca cola.

In order to really be sure that AQs can associate with an unmarked focused object, we therefore have to fall back on strategy (D). In (26ab), the focus constituents of the first clause, marked by italics, are controlled for by the structure of the negative contrastive clause:

$$
\begin{aligned}
& \text { a. Gaalìbii Hàwwa ta-nàa dafà waakee, baa-tà } \\
& \text { usually Hawwa 3sg.f-prog cook beans NEG-3sg.f. } \\
& \text { 'Normally, Hawwa cooks beans, not rice.' }
\end{aligned} \begin{aligned}
& \text { dafà shìnkaafaa } \\
& \text { cook rice }
\end{aligned}
$$

As the paraphrases show, the AQ gaalibii 'usually' associates with the object in (26a) and with the VP in (26b). Based on (26ab), we can therefore conclude that AQs in Hausa can associate with various constituents in the absence of grammatical focus marking.

More generally, the sentences in (24) to (26) support Beaver \& Clark's (2003) claim that material that is not grammatically marked for focus, be it by accent or movement, is not automatically mapped onto the restrictor of the AQ, cf. (5). Rather, part of the grammatically unmarked material is mapped onto the nuclear scope because it constitutes the focus constituent. In the case of Hausa, this state of affairs obtains because the informationstructural category of focus is often not marked at all. In general, given that the determination of unmarked foci in Hausa relies on pragmatic resolution based on contextual information, it follows that the association of AQs with focus in this language is a pragmatic phenomenon, rather than a grammatically hard-wired process.

\subsection{Adverbial Quantifiers vs. Focus Particles}

In section 2, English adverbial quantifiers were shown to differ from focus particles in that the former stand in a loser syntactic and semantic relation to the grammatically marked focus constituent than the latter. This section shows that the same can be said for Hausa: as in English, the association of Hausa FPs, such as sai and kawai 'only, just', with focus constituents is subject to strict licensing conditions:

The focus-sensitive particle sai can only combine with overtly focus-moved NPs, cf. (27a). It never combines with in situ focus constituents, cf. (27b) (Kraft 1970):

$$
\begin{array}{lll}
\text { a. } & \text { Bàshîr sai } \quad \operatorname{ruwaa}_{\mathrm{F}} & \text { ya kawoo } \\
\text { Bashir only water } & \text { 3sg.m.perf.rel fetch } \\
\text { 'Bashir fetched only water.' } &
\end{array}
$$

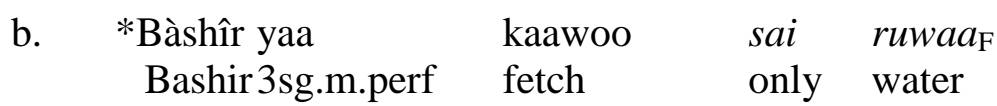

The focus-sensitive expression kawai also occurs predominantly with focus constituents that have been overtly moved to the left periphery, cf. (28ab).
a.
Littàttàafai $_{\mathrm{F}} \quad$ kawài dâalìbai
books only students
'The students bought only BOOKS.'
su-kà sàyaa.
3pl-perf.rel buy
b. ??D'àalìbai sun
sàyi littàttàafai $i_{\mathrm{F}}$
kawài. 


$$
\text { students 3pl.perf buy books only }
$$

Marginally, kawai also occurs with in situ foci. If this happens, kawai has to be adjacent to the focus constituent immediately to its left. This is demonstrated in example (29B), taken from a collection of naturally occurring discourses (Randell et al. 1998).

$$
\begin{aligned}
& \text { A: Nii kò, bá ni sôn dooyàa. } \\
& \text { I PRT NEG 1sg.cont like yam } \\
& \text { 'As for me, I don't like yams.' } \\
& \begin{array}{lllllll}
\text { B: } & \text { Tòo bàa } & \text { sai } & \text { kì } & \text { ci } & \text { shìnkaafaa }_{\mathrm{F}} & \text { kawài ba? } \\
& \text { PRT NEG } & \text { then } & \text { 2sg.subj } & \text { eat } & \text { rice } & \text { only Q }
\end{array} \\
& \text { 'Well, but you don't eat only rice, don't you?' }
\end{aligned}
$$

As is clear from the immediately preceding context in (25A), the focus constituent in (25B) must be the object NP shinkafa 'rice', which is immediately followed by the focus-sensitive particle kawai.

The data in (27) to (29) show, then, that the FPs sai and kawai 'just, only' are in need of a clearly identifiable focus constituent with which to associate semantically. This constituent can be identified on the base of two criteria: First, the FPs are adjacent to it. In addition, the focus constituent plus FP are obligatorily ( $\mathrm{sai}$ ) or frequently (kawai) moved to the overt focus position in the left periphery of the clause. Similar facts hold for the FP kadai 'only', and for the particle nee/cee (Hartmann \& Zimmermann, to appear-b).

The fact that Hausa FPs are in need of a clearly identifiable focus constituent argues for a syntactic and semantic specification in their lexical entry. FPs in Hausa appear to subcategorize for a nominal focus constituent with which they also associate semantically. Following Beaver \& Clark (2003), one can capture this behaviour of FPs by specifying them as [+ focus-functional] in their lexical entry. On the other hand, we have seen that AQs do not impose similar restrictions on the grammatical realisation of the focus constituent. The focus constituent need not be marked, and the AQ does not generally occur adjacent to it. The difference in syntactic and semantic behaviour of AQs and FPs thus suggests a categorical distinction between the two types of expressions: While FPs are [+ focus-functional], AQs can be analysed as [- focus-functional], again following Beaver \& Clark (2003).

To conclude, surface differences aside, the observed differences between AQs and FPs in Hausa appear to replicate similar differences between AQs and FPs in English and other intonation languages. Again, this similarity suggests that essentially the same basic mechanisms of interpretation are at work in both language groups. In the next section, we will therefore proceed to sketch a unified account of the interpretation of AQs in Hausa and in intonation languages.

\section{AQs in Hausa and Intonation Languages: A Unified Analysis and a Prediction}

In the preceding section, Hausa AQs were shown to resemble their counterparts in intonation languages when it comes to the association with constituents that are overtly marked for focus (section 5.1), and the differences between AQs and FPs (section 5.3). Furthermore, we concluded in section 5.2 that the association of Hausa AQs with focus is pragmatically governed. This conclusion is in line with Beaver \& Clark's (2003) findings for AQs in intonation languages (section 2), and more generally with other pragmatic approaches to focus-sensitivity and focus, see e.g. Rooth (1992), Dryer (1994), Roberts (1996), Büring (1997), and Kadmon (2001). From a theoretical perspective, then, the Hausa facts can be taken as evidence in favour of such more pragmatic approaches to the focus sensitivity of AQs over more grammaticized analyses that crucially rely on grammatical focus marking. 
Given the observed similarities between Hausa AQs, on the one hand, and AQs in intonation languages like English on the other, it is tempting to come up with a unified analysis for AQs in both types of languages. The analysis, as sketched in (30), is based on Beaver \& Clark's (2003) analysis of English AQs, see section 2.

Unified Analysis of AQs in Hausa and Intonation Languages:

i. $\quad$ AQs take their whole clause as nuclear scope. (see also Partee 1999)

ii. The restriction is not provided by the grammar, but is pragmatically determined.

iii. In intonation languages, and with instances of grammatically marked focus in Hausa, the restriction of the AQ must be compatible with all presuppositions, including those stemming from grammatical focus marking.

iv. With unmarked focus in Hausa, the restriction must be compatible with the contextual information that determines the locus of focus.

The discussion of Hausa AQs is of interest to the discussion of AQs in English and other intonational languages for yet another reason: the Hausa data observed show clearly that there is no inherent need for grammatical focus marking with AQs. In intonation languages such as English, the picture is not so clear because it is blurred by the obligatory occurrence of a nuclear pitch accent in all sentences. In other words, English AQs are always accompanied by a clause-mate nuclear pitch accent, but possibly for independent reasons. Motivated by the facts from Hausa, then, one could adopt a more radical position and speculate that English AQs, too, do not require a constituent to be grammatically marked for focus in order to associate with it.

In order to find out whether or not this claim is correct, we have to find out if there are ever configurations in English in which an AQ can co-occur with a grammatically unmarked, i.e. fully destressed focus constituent. Previous studies have shown that FPs cannot: Rooth (1996) and Beaver et al. (2004) show that the associates of FPs such as only must be grammatically marked. If marking by pitch accent is impossible, e.g. with instances of so-called second occurrence focus (SOF), in which the associate of the FP is given and therefore blocked from carrying a nuclear pitch accent, it is marked by duration and intensity instead (see also Féry \& Ishihara, to appear).

Given the observed differences between AQs and FPs, one may therefore wonder if English AQs behave differently in SOF-contexts. More precisely, the question is whether there is any kind of prosodic marking on the SOF bicycles in (31c), an example adapted from Beaver et al. (2004):

(31) a. Both Peter and his siblings spent their youth with petty crimes and theft.

b. Peter always stole [BICYCLES $]_{\mathrm{F}}$.

c. Even his youngest brother PAUL always stole [bicycles $]_{\mathrm{F}}$.

If there is no prosodic marking on bicycles, English AQs will be fully identical to their Hausa counterparts in terms of grammatical behaviour. In particular, there will be nothing in the lexical entry of an English AQ that would require the AQ to co-occur with a prosodically marked constituent. If bicycles was prosodically marked, however, this could indicate that English AQs are not fully parallel to Hausa AQs after all, and that they are dependent on some sort of focus marking for the identification of the relevant background presuppositions that constrain the restriction of the AQ to take place. Hopefully, future phonetic studies of AQs in SOF-contexts will help to clarify this issue. 


\section{Conclusion}

In this paper, I have investigated the semantic interaction of adverbial quantifiers and focus marking in Hausa. The main result was that intonation and tone languages such as Hausa do not differ fundamentally when it comes to the association of AQs with focused elements, despite the fact that focus marking in Hausa works quite differently. This may hint at the existence of universal mechanisms behind the interpretation of adverbial quantifiers across languages.

\section{References}

Beaver, D. and Clark, B.: 2003, Natural Language Semantics 11(4), 323-362.

Beaver, D., Clark, B., Flemming, E., Jaeger, F.T., and Wolters, M.: 2004, When Semantics Meets Phonetics: Acoustical Studies of Second Occurrence Focus, Ms., Stanford University.

Büring, D.: 1997, The Meaning of Topic and Focus-The 59th Street Bridge Accent. London: Routledge.

Chafe, W.L.: 1976: Givenness, Contrastiveness, Definiteness, Subjects, Topics, and Point of View, in C. Li (ed), Subject and Topic, London, New York: Academic Press, pp.26-55.

Cohen, A.: 1999, How Are Alternatives Computed?, Journal of Semantics 16, 43-65.

Dryer, M. S.: 1994, The pragmatics of association with only. Paper presented at the 1994. Winter Meeting of the L.S.A. Boston, Massachusetts.

Féry, C., and Ishihara, S.: to appear, Interpreting second occurrence focus, in S. Ishihara \& M. Schmitz (eds.), Interdisciplinary Studies on Information Structure. University of Potsdam.

von Fintel, K.: 1994, Restrictions on Quantifier Domains, Ph.D. dissertation, University of Massachussetts, Amherst.

Givón, T.: 1976, Topic, Pronoun and Grammatical Agreement, in C. Li (ed), Subject and Topic, London, New York: Academic Press, pp. 151-188.

Green, M.: 1997, Focus and Copular Constructions in Hausa, PhD Dissertation, SOAS, London.

Green, M. and Jaggar, P.: 2003, Ex-situ and in-situ focus in Hausa: syntax, semantics and discourse, in J. Lecarme, J. Lowenstamm and U. Shlonsky (eds), Research in Afroasiatic Grammar 2, Amsterdam: Benjamins, pp. 187-213.

Hartmann, K. and Zimmermann, M.: 2004, Focus Strategies in Chadic: The Case of Tangale Revisited, in S. Ishihara, M. Schmitz and A. Schwarz (eds), Interdisciplinary Studies on Information Structure (ISIS) 1, Potsdam: Universitätsverlag Potsdam, pp. 207-244.

Hartmann, K. and Zimmermann, M.: to appear-a, In Place - Out of Place: Focus in Hausa, in K. Schwabe and S. Winkler (eds), On Information Structure, Meaning and Form. Amsterdam: Benjamins. 
Hartmann, K. and Zimmermann, M.: to appear-b, Exhaustivity Marking in Hausa: A ReEvaluation of the Particle nee/cee, in E. Aboh, K. Hartmann, and M. Zimmermann (eds), Focus Strategies: Evidence from African Languages (Niger-Congo. Afro-Asiatic, West-Atlantic), Berlin: de Gruyter.

Heim, I.: 1990, E-type Pronouns and Donkey Anaphora, Linguistics and Philosophy 13, 137-177.

Herburger, E.: 2000, What Counts. Focus and Quantification. Cambridge, Ma.: MIT Press.

Kadmon, N.: 2001, Formal Pragmatics: Semantics, Pragmatics, Presupposition and Focus. Oxford: Blackwell.

Kiss, K.E.: 1998, Identificational Focus Versus Information Focus, Language 74, 245-273.

Kraft, C. H.: 1970, Hausa sai and dà - a couple of overworked particles. In Journal of African Languages 9, 92-109.

Jaggar, P.: 2001, Hausa. Amsterdam: John Benjamins.

Lewis, D.: 1975, Adverbs of Quantification, in E.L. Keenan (ed), Formal Semantics of Natural Language, Cambridge University Press, pp. 3-15.

Matthewson, L.: 2004, On the Methodology of Semantic Fieldwork. International Journal of American Linguistics 70(4), 369-415.

McConvell, P.: 1973, Cleft Sentences in Hausa? A Syntactic Study of Focus, PhD Dissertation, SOAS, London.

Newman, P.: 2000, The Hausa Language. New Haven \& London: Yale University Press.

Partee, B. H.: 1991, Topic, Focus and Quantification, in S. Moore and A. Wyner (eds), Proceedings of SALT I, Ithaca, NY, pp. 159-187.

Partee, B. H.: 1999, Focus, Quantification, and Semantics-Pragmatics Issues, in P. Bosch and R. van der Sandt (eds), Focus: Linguistic, Cognitive, and Computational Perspectives, Cambridge University Press, pp. 213-231.

Randell, R., Bature, A. and Schuh, R. 1998. Hausa Bakar. (http://www.humnet.ucla.edu/humnet/aflang/hausarbaka/)

Roberts, C.: 1996, Information Structure in Discourse: Towards an Integrated Formal Theory of Pragmatics, OSU Working Papers in Linguistics 49. Papers in Semantics.

Rooth, M.: 1985, Association with Focus, Ph.D. dissertation, University of Massachussetts, Amherst.

Rooth, M.:1992. A Theory of Focus Interpretation. Natural Language Semantics 1, 75-116.

Rooth, M., 1996. On the Interface Principles for Intonational Focus, in T. Galloway and J. Spence (eds), Proceedings of SALT VI. Ithaca, NY, pp. 202-226.

de Swart, H.: 1991, Adverbs and Quantification : A Generalized Approach, PhD dissertation, University of Groningen.

Tuller, L.: 1986, Bijective Relations in Universal Grammar and the Syntax of Hausa, PhD Dissertation, UCLA, Los Angeles. 